\title{
SOBRE UN ROMANCE NOTICIERO
}

Vaya el texto por delante, para deleite y conocimiento de todos.

Romance de Juan de Leyva a la muerte de Don Manrrique de Lara

A veynte y siete de março, la media noche sería, en Barçelona la grande muy grandes llantos había. Los gritos llegan al cielo, la gente s'amortescía por Don Manrrique de Lara que deste mundo partía. Muerto lo traen a su tierra donde biuo sucedía; su bulto lieua cubierto de muy rica pedrería; cercado d'escudos d'armas de real genalogía d'aquellos altos linajes donde aquel señor venía. De los Manrriques y Castros el mejor era que auía; de los Infantes de Lara derechamente venía. Con él sallen Arçobispos con toda la clerezía, caualleros traen sus andas, duques son su compañía; llóralo el Rey y la Reyna como aquel que les dolía; llóralo toda la corte, cada qual quien más podía. Quedaron todas las damas sin consuelo ni alegría; cada vno de los galanes con sus lágrinias [sic] dezía: -El mejor de los mejores oy nos dexa en este día-. Hizo honrra a los menores, a los grandes demasía, parescía al Duque su padre en toda cauallería. Sólo vn consuelo le queda a el que más le quería [sic], que aunque la vida muriesse su memoria quedaría. Parescióme Barçelona a Troya quando se ardía.

Desfecha.

El triste que se partió deste mundo mal logrado, éste deue ser llorado.

La luz crescida muy clara es perdida ya en la corte, luzero estrella de norte 
fue Don Manrrique de Lara;

pues la muerte tanto cara deste mundo lo ha lleuado, éste deue ser llorado.

Tal es el texto del Cancionero general de Hernando del Castillo (Valencia, Cristóbal Kofman, 1511), f. cxxxv v ${ }^{\circ}$. Poco después se imprimió el romance sin desfecha en el Cancionero llamado Guirlanda esmaltada de enamorados (s.l.n.a., pero hacia 1520), también conocido como Cancionero de Juan Fernández de Costantina. Asimismo sin desfecha se copió el texto en el Cancionero de romances (Amberes, Martín Nucio, s.a.), f. 236. Lo mismo ocurre en el Cancionero de romances (Amberes, Martín Nucio, 1550), y así, sin desfecha lo imprimió Agustín Durán en su usadísimo Romancero general, núm. 963. Con algunas variantes (comenzando por el título, "Romance de Juan de Leyva a la muerte de Don Jorge Manrique de Lara") se halla en Espejo de enamorados (s.l.n.a.), y aquí se mantiene la desfecha. A esta amplia difusión de nuestro romance probablemente contribuyó el hecho de que fue puesto a música, preparado para el canto, y esta música se conserva en el Cancionero musical de la Casa de Medinaceli (Siglo xvi), I: Polifonía profana ${ }^{1}$. Todos estos datos ayudan a explicar el hecho de que este romance noticiero llegó a adquirir un cierto grado de tradicionalización, como parece indicar la cita del gran historiador y genealogista del siglo XVII Don Luis de Salazar y Castro: "En Barcelona la grande grandes llantos se hacían / por Don Manrique de Lara que deste mundo partía. / Llóranle duques y condes, llora la cavallería" (Historia genealógica de la Casa de Lara, II, Madrid, 1697, 143).

Se trata de un romance noticiero, género que adquiere gran popularidad en la época de los Reyes Católicos, para desaparecer a finales de su reinado. Narra la muerte de Don Jorge Manrique de Lara, hijo mayor de Don Pedro Manrique de Lara, II Conde de Treviño y I Duque de Nájera, vale decir, se hace cargo de la muerte del primogénito y heredero del pariente mayor de la poderosa familia de los Manrique. El I Duque de Nájera fue primo hermano del famoso poeta y guerrero Jorge Manrique, como que fue hijo de Don Diego Manrique, I Conde de Treviño, hermano mayor del Maestre de Santiago Don Rodrigo Manrique, el padre del poeta e inspirador de sus conocidas Coplas por la muerte de

${ }^{1}$ Ed. de M. Querol Gavaldá, Barcelona, 1949. Véase en especial el t. 1, pról., pp. 35-36, texto 14 . 
su padre. Esto ayuda a explicar el nombre de pila del difunto caballero cantado en nuestro romance.

El cantor de la muerte del primogénito de la Casa de Nájera fue otro riojano, casi desconocido como poeta pero no ajeno a las páginas de la Historia. Juan de Leyva (Leiva), también conocido por la forma completa de su apellido como Juan Martínez de Leyva, fue retratado de cuerpo entero por la eminente pluma de Gonzalo Fernández de Oviedo al escribir esto:

En esa comarca e ánbito de Rrioja cae el antiguo e illustre solar e casa de Leyua, de la qual fue Señor, e yo le conocí, al anciano e valiente cauallero capitán de cient ombres de armas de los Rreyes Cathólicos que ganaron a Granada e Nápoles, Johan Martínez de Leyua, cabeça deste linaje e mayordomo, cuyo hijo mayor e sucesor de su casa fue Sancho Martínez de Leyua, e el segundo hijo fue este señor Antonio de Leyua, Príncipe de Áscoli, en el reyno de Nápoles, capitán general de la Çesárea Magestad del Emperador Don Carlos 5, nuestro señor ${ }^{2}$.

Don Ramón Menéndez Pidal había recogido noticias de la actuación de Juan de Leyva en la conquista de Málaga (1487) y lo había identificado, correctamente, como mílite de la Casa de Nájera3. "Caballero y contino de la Casa del Duque Don Pedro Manrique de Lara" es como le identificó Joaquín Durán y Lerchundi'. En marzo de 1476 Juan de Leyva había participado, con la gente de Don Pedro Manrique de Lara, en la desgraciada defensa de Rentería (Guipúzcoa). La última guerra de Granada lo llevó a estas tierras como caballero y contino de la Casa de Don Pedro, y su presencia en la conquista de Málaga está corroborada por Francisco Henríquez de Jorquera, quien cita a Antonio de Nebrija (Rerum a Fernando et Elisabe gestarum Decadas) ${ }^{5}$. Al final de la guerra (1492) es de suponer que volvió a sus tierras riojanas, porque en su romance de 1493 dice que al difunto Don Man-

${ }^{2}$ En el autógrafo de sus Quinquagenas de la nobleza de España que yo publiqué con el título de Las memorias de Gonzalo Fernández de Oviedo, Ghapel Hill, NC, 1974, t. 1, pp. 235-236.

${ }^{3}$ Romancero hispánico, Madrid, 1953, t. 2, pp. 54-55.

${ }^{4}$ La toma de Granada y caballeros que concurrieron a ella, Madrid, 1893, t. 2, apéndice VI, "'Los caballeros y continos de la casa del Duque Don Pedro Manrique", pp. 42-43.

${ }^{5}$ Henríquez de Jorquera, Anales de Granada, ed. A. Marín Ocete, Granada, 1934 , t. 1 , p. 430. 
rique "muerto lo traen a su tierra", lo que parece indicar que Leyva poetizaba en La Rioja. Estos pocos datos bastan para aseverar que nuestro romance da noticia de algo que le tiene que haber dolido en el alma a Juan de Leyva.

La esencia de los romances noticieros es hacerse cargo de algún aspecto de la realidad histórica inmediata, por lo cual tiene interés ahora bosquejar los personajes del elenco de nuestro romance. Comienzo por el padre del llorado joven, Don Pedro Manrique de Lara, I Duque de Nájera, famoso guerrero aun dentro del belicosísimo clan de los Manrique, al punto que mereció los honores de una particular biografía, lo que lo convierte en el único personaje de la época de los Reyes Católicos así honrado: Hazañas valerosas y dichos discretos del Ilmo y Excmo. Sr. D. Pedro Manrique de Lara, primer Duque de Nájera, Conde de Treviño, Señor de las villas y tierras de Amusco, Navarrete, Redecilla, San Pedro de Yanguas, Ocón, Villa de la Sierra, Genebrilla y Cabreros. ${ }^{6}$. Allí se nos informa que

su persona fue nombrada y estimada por su gran valor, no sólo entre christianos mas entre moros; fue hombre de mediana estatura y bien fornido de miembros, el rostro largo y de hermosas facciones: era su aspecto tan grave y de tanta autoridad que qualquiera que le viera en hávito común sin conocelle, le juzgara por señor.

La educación de este bravo guerrero estuvo fuera de lo común, como nos recuerda el anónimo biógrafo:

Siendo el Duque Conde de Treviño y mochacho, se le alçó con su estado la Condessa [de Treviño] Doña María de Sandobal, su madre, y con el conssejo de sus tíos el Maestre [de Santiago] D. Rodrigo Manrrique, Conde de Paredes, y Pero Manrrique, Señor de Val de Ezcaray, y Garci Hernández Manrrique, hermanos de su padre, lo cobró echando de él a su madre y todos sus valedores. Estos caballeros tuvieron mucho cuydado en criar bien [a] este Conde, su sobrino, no tierna ni delicadamente, sino ejercitándole en cossas de guerra, y assí salió en ella consumado, diestro y animosso, que no se puede juntamente deçir que huviese en estos reynos cavallero ni señor que mejor que él las entendiesse ni ejercitasse.

El verso del romance "Parece al Duque su padre en toda caballería" no es, por consiguiente, declaratorio, sino que se eleva a las alturas de la hipérbole. Con tales maestros no debe extra-

${ }^{6}$ Memorial Histórico Español, Madrid, 1853, t. 6, pp. 121-146. 
ñar que Don Pedro llegase al punto que "decía qué mal yría a los Manrriques quando se diessen a olores y perfumes; no consintió que adonde estaban sus hijas y mugeres entrase ningún criado suyo, ni aun sus hijos, porque decía que lo que no ven los ojos no lo dessea el coraçón'. Pero el arrogante gran señor no siguió su propio consejo, porque aunque casado con la dama portuguesa Doña Guiomar de Castro, la tenía abandonada y vivía amancebado con su prima Doña María de Sandoval, lo que le provocó grave reconvención de la Reina Católica y un nuevo soberbio desplante suyo:

Escrivióle el Cardenal D. Pedro Gonçález de Mendoça al Duque [de Nájera] que la Reyna avía savido el pecado en que estaba con Doña María de Sandoval, su prima, que le remediasse, sino que Su Alteça le castigaría. Respondióle el Duque: "Rmo. Señor, no tengo yo a la Reyna, nuestra señora, por tal que hará de la justiçia missa mozárabe, que primero mandará Su Alteça castigar a los putos que a los putañeros'"?.

Como nos informará el cronista Gonzalo Fernández de Oviedo, en el interesante texto que copio más abajo, estás relaciones ilícitas del Duque provocaron graves desavenencias entre Don Pedro y su primogénito, a quien está dedicado el romance noticiero. Por lo demás, el hecho de que su madre fuese Doña Guiomar de Castro explica otro verso del romance: “De los Manriques y Castros el mejor era que había'.

Como nos explica el mismo Fernández de Oviedo en el interesantísimo autógrafo que citaré, “ "el Duque primero [de Nájera] tuuo dos hijos legítimos, e el mayor dellos llamado Don Manrrique de Lara murió en vida del padre, mançebo. E suçedió en la casa el segundo hijo, Don Antonio Manrrique"'. Éste fue el II Duque de Nájera, quien, a su vez, tuvo como hijo a Don Juan Esteban Manrique de Lara, III Duque de Nájera, y apostilló Oviedo: "A todos los tres conosçimos".

${ }^{7}$ Las famosísimas Coplas del Provincial no dejan muy bien parado al futuro Duque de Nájera ni a su madre Doña María de Sandoval: “De Treviño fraile y conde, / Manrique de Sandoval, / la verdad nunca se esconde, / bien la sabe el Provincial, / pues de hoy más por el escote / podeis poner por reseña, / no os podrán poner por mote / hijo de la casta dueña". Una de las preguntas iniciales de estas Coplas también parece estar asestada contra la misma señora y sus extrañas relaciones con los Manrique: “ ¿Por qué haces adulterio / con la mujer de tu hermano?" 
La muerte imprevista de Don Jorge Manrique de Lara, heredero de tan fastuosa casa, no dejó de tener repercusión en la cronística de la época. El llamado Cronicón de Valladolid, formado sobre notas tomadas por el doctor Toledo, médico de la Reina Católica, apunta lo siguiente:

Murió Don Manrique de Lara, fijo primogénito de Don Pedro Manrique, Duque de Nájera, día martes después de mediodía, año de 1493: murió cerca de medianoche. Fue llevado a enterrar al monesterio de Nuestra Señora de Valvanera. Era hijo del dicho Duque y de Doña Guiomar de Castro ${ }^{8}$.

La poesía cortesana también se hizo cargo de tan desastrada muerte. En su famoso y aclamado poema Infierno de amor Garci Sánchez de Badajoz finge ver allí a Don Manrique de Lara ya muerto:
$\mathrm{Vi}$ a Don Manrrique de Lara como ombre muy aborrido, su pena escura muy clara, de todas partes herido, muerta la flor de su cara: por el suelo vi tendida su real sangre vertida, sin guardarle preminencia, diziendo muy sin paciencia: Desespérese mi vida de sanar desta dolencia.

El título con que se publicó esta composición en el Cancioner general de Hernando del Castillo (Valencia, Cristóbal Kofman 1511) fue el siguiente: "Coplas del dicho Garci Sánchez a los ga lanes fingiendo que los vido presos en la casa d'amor a los biuo: y a los pasados, con las canciones que hizieron. Llámase Infiern de amor'. Se debe inferir, por consiguiente, que los dos último: versos copiados pertenecen a una canción de Don Manrique di Lara. No conozco otras composiciones suyas, pero es muy pro bable que el joven aristócrata fuese poeta, en una época en qur el versificar casi era connatural a la nobleza ${ }^{9}$.

${ }^{8}$ Publicado con notas por Pedro SÁinz de Baranda, Colección de documen tos inéditos para la historia de España, Madrid, 1848, t. 13, pp. 7-228. La cita de texto es de la p. 203.

${ }^{9}$ Véase Patrick Gallagher, The Life and Works of Garci Sánchez de Badc 
Enamorado y poeta es como pinta a Don Manrique de Lara el poeta cortesano Tapia en la composición que lleva este título: "Otra obra suya a vna partida que hizo de la corte Doña Mencía de Sandoual, y él, viendo quán tristes quedauan sus seruidores, habla en persona de cada vno dellos, y dize lo que ellos podían dezir'. El primer aristócrata galán y poeta que hace hablar Tapia es Don Fadrique de Toledo, Duque de Alba, seguido por Don Fadrique Enríquez, Almirante de Castilla, después Don Pedro de Toledo y el cuarto es nuestro Don Manrique de Lara, en cuya boca Tapia pone esta copla real:

$$
\begin{aligned}
& \text { Pues yo, señora, en partirme } \\
& \text { y veros a vos partir } \\
& \text { desseo tanto morirme, } \\
& \text { que no podría venirme } \\
& \text { mejor cosa que el morir. } \\
& \text { Assí que al triste que duele } \\
& \text { este dolor y su suerte, } \\
& \text { por bien su lloro buele, } \\
& \text { conuiene que se consuele } \\
& \text { con ver el mal de su muerte. }
\end{aligned}
$$

(Cancionero general, f. clxxvi $\mathrm{v}^{\mathrm{o}}$ ).

Los Reyes Católicos habían llegado a Barcelona ("En Barcelona la grande muy grandes llantos había") el 18 de octubre de 1492 y allí permanecieron hasta comienzos de septiembre de 1493. Esta larga estancia fue puntuada trágicamente por el violento atentado contra la vida del Rey Católico por el payés Juan de Canyamés (viernes 7 de diciembre de 1492), como recordará Fernández de Oviedo, quien estuvo presente a todo esto como mozo de cámara del príncipe heredero Don Juan. El 27 de marzo de 1493 murió en Barcelona y al servicio de sus Reyes el llorado Don Manrique de Lara. Para mayo del mismo año ocurrió la fastuosísima entrada en Barcelona de Cristóbal Colón, recién llegado de su inmarcesible viaje. Y los Reyes permanecieron en Barcelona hasta noviembre de 1493 , con breves viajes comarcales.

Tal es el trasfondo histórico de nuestro romance noticiero. Ahora bien, la muerte aquí cantada es la del heredero de la Casa de Manrique (1493), Casa que en 1479 había perdido a uno de los

joz, London, 1968, p. 103; desgraciadamente en pp. 216-218, Gallagher identifica a Don Manrique de Lara con su padre Don Pedro y procede a desbarrar en serio. 
más grandes poetas de la lengua castellana, Jorge Manrique, tío del muerto cantado por Juan de Leyva. La fama del poeta Manrique descansaba, y descansa, en parte mayor, sobre las Coplas a la muerte de su padre, que, aparte de su valor poético universal, son un himno a la gloria y a la integridad de la familia Manrique, encarnada en el recién muerto Maestre de Santiago, su padre. Es natural que un novel cantor de otro ilustre muerto del solar manriqueño poetice desde dentro de la tradición específica y ya bien establecida de dichas Coplas. Desde este ángulo de visión los versos finales del romance de Juan de Leyva adquieren resonancias adicionales:

El mejor de los mejores hoy nos deja en este día.

Hizo honra a los menores, a los grandes demasía; parece al Duque su padre en toda caballería.

Sólo un consuelo le queda y es el que él más quería, que aunque la vida muriese su memoria quedaría.

Alusión y elusión a dos famosos pasajes de las Coplas se traslucen en los versos citados. El primero forma parte del elogio del difunto Maestre de Santiago; en general, coplas 26-28, en particular estos versos: "Qué benigno a los subjetos, / y a los bravos y dañosos / un león". El segundo se refiere a los últimos versos de las Coplas: "Y aunque la vida murió / nos dexó harto consuele / su memoria". O sea que Juan de Leyva apuntala su romance sobre una espontánea recreación de las Coplas, que para un servidor de los Manrique tenían que considerarse como patrimonic familiar. El romance "A veinte y siete de marzo" adquiere nuevas tonalidades al leerse desde el cuadrante de las Coplas, inten. cionalidad poética desde la que debe haber partido Juan de Leyva

El telón histórico contra el que hay que leer nuestro romance queda cumplidamente ilustrado por un texto del "Néstor de los cronistas de Indias" - expresión de mi querido amigo Eugenic Asensio-, Gonzalo Fernández de Oviedo. Proviene de sus Bata llas y quinquagenas, un interesantísimo tratado, escrito en forma $\mathrm{de}$ diálogos entre el Alcaide y el Sereno (dos voces del autor, alcaidt de la fortaleza de Santo Domingo), acerca del estado socio económico de las grandes familias españolas en su época, cad: diálogo basado en personajes históricos que él había conocido. Po. su propia descripción resulta evidente que cada quinquagena cons taba de cincuenta diálogos y cada batalla de cuatro quinquagenas La obra quedó sin terminar, pero estaba planeada con las mons 
truosas dimensiones de ochocientos diálogos: 4 batallas $\times 4$ quinquagenas $\times 50$ diálogos $=800$ diálogos. He tenido la fortuna de encontrar el perdido autógrafo de esta obra de extraordinario interés, aunque en estado bastante desmedrado. El precioso autógrafo se conserva en la Biblioteca Universitaria de Salamanca, y consta de 132 diálogos, y todo lo publiqué en 1989, auspiciado por la Diputación de Salamanca.

Allí Oviedo dedicó al joven aristócrata llorado por Juan de Leyva en su romance noticiero un diálogo completo (pp. 346-349 de mi edición), que dota de cierto calor vital a esta figura que el correr del tiempo ha reducido a la categoría de un fantasma de la Historia, y que por la meridiana luz que derrama sobre esta poesía copio a continuación en su integridad.

El muy jllustre señor Don Manrrique de Lara, primogénito mayoradgo de la casa del Duque primero de Nájera Don Pedro Manrrique. Batalla 2a., quinquagena 3a., diálogo v.

ALCAIDE Don Manrrique de Lara, hijo mayor del primero Duque de Nájera Don Pedro Manrrique, cuyo suçessor esperaua ser en su casa y estado, e si le diera Dios tanta vida que al padre vençiera de días. E perssona le avía dado para ésse e otro mayor estado. Fue tal biuiendo que a todos dexó çertificados que lo eredó Dios mejor en la otra vida de lo que en ésta pudiera dessear. Porque entre los caualleros mançebos fue en su tiempo vn norte e espejo de toda gentileza, ajeno de viçios y colmado de virtudes, y el más bien quisto cortesano que se ha visto gran tiempo ha. Pero en su temprana muerte e forma della desdichado y el más llorado cortesano de todos quantos yo en mi tiempo he visto nj sabido. Fue muy agrasçiado e de gentil dispusiçión, jamás tuuo cosa que si él pudiese dar que fuese suya e quando se lo pedían él se acomodaua a darlo e diziendo ser tal que quisiera darlo al que la rresçebía.

SERENO ¿De qué manera murió?

AlCAIDE Murió en la flor de su edad, que podría ser de treinta años o menos. E salió desta vida en Barçelona, a XXVIJ días de março de 1493 años de achaque de ave- pocos días antes beuido vn jarro de agua fría estando sudando e jugando a la piedra gruesa en vna calle con otros caualleros mançebos, e rresfrióse e aquése fue el prinçipio de su mal e diole vna fiebre tal que sin se le [una palabra ilegible] en pocos días le mató. Podeys aver por çierto que dexadas aparte las perssonas de los Rreyes Cathólicos y de sus hijos no pudiera ombre morir en España tan llorado como fue Don Manrrique de Lara, que tan lutuosa e triste dexase la corte, porque era muy querido en ella entre los señores e caualleros e damas y de tos [sic por todos] los que aquella corte seguían. Y pues viene a propósito deziros he lo que pocos meses antes hizo e proueyó, quando vn traydor llamado Juan de Cañamares dio vna cuchillada al sereníssimo rrey Don Fernando, de que llegó a punto de muerte. E estuuo aquel día aquella çibdad de Barçelona puesta en armas e a mucho peligro quantos allí se hallaron a causa de aquella trayçión. 
SERENO Holgaré que lo digays pues allí hos hallastes, que no sería ese día de poca turbaçión, nj de menos peligro e escándalo.

ALCAIDE Óvole tan grande que fue milagro de Dios no aver mucha sangre derramada por todas las calles e casas e plaças de Barçelona, con que qualquier desatinado ombre echara mano a vna espada e començara la pelea o rruydo.

SERENO Tenés mucha rrazón de penssarlo así, porque en tan grande ocasión e caso semejante fue menester la clemençia diuina para no se rreboluer vn ombre con otro [una palabra ilegible] grande número de gentes e [una palabra ilegible] sus condiçiones e lenguas. Así proseguid, e dezidme el origen o prinçipio de su trayçión e lo que dezís que proueyó e hizo ese día Don Manrrique de Lara.

ALCAIDE Fue desta manera: AVÍAN los catalanes e vniuersidad de Barçelona suplicado al Rey que los oyese çerca de algunas cosas que jmportauan a su rreal seruiçio e al buen gouierno e su çibdad e de toda Cataluña. E el Rrey se lo conçedió e fue a les dar audiençia a la casa rreal del consistorio que allá llaman Palau Nou (palaçio nueuo), o casa de ayuntamiento, para entender en lo ques dicho. La qual es çerca de la Seu o yglesia cathredal. E la Rreyna e el Prínçipe e las Jnfantes quedauan en su palaçio, que era en la calle que está entre la mar e el Carrer Amplo, detrás del monesterio de Nuestra Señora de la Merçed, ques muy apartado del Palau Nou. E al tiempo quel Rrey salió de aquel consistorio baxó vna ancha escalera de piedra que está descubierta e fuera del dicho palaçio hasta vna plaçeta questá delante dél. E al tiempo que yua a poner el pie en el estribo de la mula para se yr a comer llegó aquel traydor por detrás e diole vna muy gran cuchillada como ya os tengo dicho, e se tocó esto en la primera parte o batalla destos nuestros diálogos, en el 36 de la 2a. quinquagena, donde se tractó de mossén Furiol, e allí podés tornarlo a ver ${ }^{10}$, por no tornar aquí a escriuir lo mjsmo duplicadamente. Pero deziros he lo que haze al caso de Don Manrrique e de su esfuerço e prudençia, que fue muy señalada cosa aquel día. Como se estendió la fama por toda la çibdad, publicándose que al Rrey avían muerto, todos se pusieron en armas. Vnos dezían quel malhechor era françés, e otros dezían que era aragonés, e otros le hazían castellano, e otros catalán, como lo era e loco, e natural de vn pueblo llamado Rremensa de Canto, a seys leguas de Barçelona. E como el Rrey era buen prínçipe e amado de sus súbditos, andauan las calles llenas de gente armada, atónitos, e de vnas partes a otras. Don Manrrique de Lara, como zeloso del serujçio de sus prínçipes e prudente, fue vno de los que primero fueron a palaçio a la Rreyna, que ya se lo avían dicho, e díxole: "Señora, estése queda vuestra Alteza y el Prínçipe e Jnfantas, e póngase rrecabdo en vuestras perssonas rreales, que a pessar de todo el mundo vuestros castellanos os defenderán e pornán en saluo". E la Rreyna, sin echar lágrimas, con vn coraçón grande e rreal e de más que muger prouevó luego en que vnas galeras que allí avía de vn mossén Bosquet se llegasen a tierra para meter al serenísimo Prínçipe Don Johan e a las Jnfantas, sus hermanas, dentro e ponerlos en otras dos naos castellanas questauan surtas, e la vna gallega, algo desuiadas de la costa, porques playa

${ }^{10} \mathrm{El}$ diálogo de mosén Furiol no se conserva en el autógrafo de Oviedo. 
y desabrigada. E Don Manrrique, con muchos caualleros castellanos e cortesanos e criados de la casa rreal, començaron a se hazer fuertes e barrearse, e pusieron a las bocas de las calles del palaçio, donde conuenía, guardas de perssonas nobles e calificadas, bien acompañadas. E de allí adentro no dexando entrar en la calle sino a los castellanos e cortesanos e perssonas conosçidas. E a éstos acudían sus criados e todos los que no eran catalanes e de la çibdad ninguno dexauan entrar en la calle. Estando así fechos fuertes e proueyéndose de más armas, e las galeras açercándose a tierra e aperçebidos por la Rreyna e escogidos e nombrados algunos caualleros para que entrasen en las galeras con sus hijos. E todo lo ques dicho en menos tiempo que la quarta parte de vn quarto de ora, llegó a todo correr el Jnfante Don Fernando de Granada ${ }^{11}$ (hermano del rrey que la perdió), sobre vn cauallo castaño, en cuerpo, con vn sayo de brocado rraso en vna caperuça parda de paño atestada en la cabeça, ceñjda vna espada e vn puñal en la çinta, con vna lança gineta en la mano e vna daraga danta ${ }^{12}$ embraçada. E apeóse a la puerta de palaçio e echó la rrienda en tierra por ençima de las orejas del cauallo, e puso en el arzón la daraga e arrimó la lança a la pared a par de la puerta de palaçio. E todo esto muy suelta e prestamente fecho, pero encontinente se puso a par dél Don Manrrique e otros caualleros cortesanos, e le dixo: "Señor Jnfante, ¿el Rrey; nuestro señor, es biuo, e venís de donde está su Alteza?' 'E el Jnfante rrespondió a Don Manrrique e dixo: "Sí, señor Don Manrrique". E Don Manrrique rreplicó e dixo: "Señor, dezidnos la verdad como buen cauallero". E el Jnfante rreplicó e dixo: "Señor, a fe de cauallero que yo la digo e lo vengo a dezir a la Rreyna, nuestra señora, por mandado del Rrey, nuestro señor". "Pues, señor", dixo Don Manrrique, "entre vuestra Señorja e dígalo a su Alteza"13. E así entró e subió adonde la Rreyna estaua con el Prinçipe e con las Jnfantas Doña Johana e Doña María e Doña Gatalina. Porque su hija mayor, Doña Ysabel, Prinçesa de Portugal que estaua biuda, como supo quel Rrey estaua herido, caualgó a las ancas de vna mula en que acaso allegaua el onrrado e ançiano [espacio en blancol, de mediana luna palabra ilegible] de la cámara de la Rreyna e fuese al Palaçio Nueuo donde el Rrey, su padre, estaua, sin más atender. Posaua el Cardenal Don Pero Gonçález de Mendoça, Arçobispo de Toledo, en las casas del Ohispo de Barçelona, questán junto a la Seu o yglesia mayor, e muy çerca de donde avían herido al Rrey, e estaua comiendo quando le dixeron la trayçión. E saltó de la mesa así como estaua, con vna loba de chamelote morado con que comía, e corrió adonde el Rrey estaua, acompañado de muchos caualleros e criados. E vido al Rrey e hablóle pocas palabras, esforçándole, e el Rrey le rrogó que fuese a la Rreyna a la esforçar e dezir que la herida no era peligrosa, avnque lo era, y mucho. E el

11 Oviedo dedicó un diálogo perdido al Infante Don Fernando de Granada, pero sí se conserva el diálogo autógrafo de su hermano menor el Infante Don Juan de Granada, pp. 315-317 de mi ed.

12 Adarga de piel de anta.

${ }^{13}$ Este vivo y animado diálogo, propio de un novelista, ayuda a imaginarnos la emoción del anciano cronista al rememorar a muchos años de distancia el horrendo crimen de Barcelona. 
Cardenal fue luego en vna mula y en llegado a palaçio subió aonde la Rreyna estaua oyendo al Jnfante de Granada que poco antes avía llegado, como es dicho, e díxole el Cardenal como el Rrey estaua muy esforçado e que espera [sic] en Dios que no avría peligro en su vida. Estonçes la Rreyna quiso yr con el Cardenal a visitar al Rrey, e como llegó a querer baxar el escalera se amortesçió e sentó en tierra, e fue socorrida con agua e tornó en sí e enxugó su rrostro con la manga de la camisa e despidió algunas lágrimas, las quales hasta entonçes no se avían visto en ella, en este trançe. E el Cardenal terçiaua e esforçáuala, e la Rreyna se abstuuo e dexó aquel acto feminil e caualgó, e el Prinçipe, e el Cardenal e la Jnfante Doña Johana, que es la madre del Emperador, nuestro señor e señora nuestros al presente ${ }^{14}$. E fueron al palaçio donde el Rey estaua, e Don Manrrique de Lara a pie a par de la Rreyna, e otros muchos caualleros generosos que avían a palaçio acudido. E la Rreyna como vido al Rrey e le habló fue esforçándolo con alegre semblante, sin lágrimas e proueyendo en la sala e cámara del Rrey con tanta auctorjdad e vigilançia que daua admiraçión a todos los que la vían. E desos allj proueyó quel Cardenal e el Duque de Cardona, e otros señores prinçipales, atendiesen en hazer sosegar la çibdad, dándoles buenas nueuas de la salud e vida del Rrey, e notificándoles a todos que la herida de su Alteza no era mortal. E porque en esta materia yo escreuí en la segunda parte del Cathálogo rreal de Castilla basta lo que aquí está dicho al propósito de Don Manrrique de Lara, que con su esfuerço e industria bastara aquel día a que la Rreyna Cathóhca e el Prínçipe Don Johan e sus hermanas las Jufantes, todos quatro, se saluaran e pusieran en las naos ya dichas, avnquel rrestante fuera contrario, e fecho aquesso si caso fuera oue la çibdad quisiera estorbar no pudiera. E puestas las perssonas rreales donde es dicho para que se samasen, Don Manrrique estaua determinado de morir con el espada en la mano si conuiniera, e otros muchos con él, por obsequias del Rrey, e ofresçer sus vidas en bengança de su muerte. La quai, avnque muriera, no pudiera causar que la leal fe de los catalanes faltara al perjujçio rreal, porque demás destar sin culpa se hallaua en la çibdad el dicho Duque de Cardona, que eran gran señor e el prinçipal de Cataluña, e casado cor su tía del Rrey. E estaua el Jnfante Don Enrrique [una palabra ilegible]: ques Conde de Ampurias e gran señor, e primo, hijos de hermanas, de] Rrey. E estaua la casa de Rrequesens, que es gran parte en Barçelona. e otros muchos caualleros catalanes leales, e criados del Rrey que avíar de hazer el deuer. Pero, en fin, hízolo Dios mejor, e como los catalanes ninguma culpa thenían en el caso e les dolió en el ánima lo deste día er su çibdad, que dieron al delinquente por su mano tan cruel castigo comc muchos atraydos se [una palabra ilegible] e lo alcançaron biuo e le fueror desnudando de paso en paso por las calles de Barçelona, e después lo que. maron, e los poluos e cenizas echaron en la mar.

SEREno Sin dubda, como avés dicho, Don Manrrique lo hizo come

14 Juana la Loca nunca renunció al trono de Castilla y vivió encerrada en Tordesillas hasta el 12 de abril de 1555, fecha de su muerte -un año antes que la abdicación de su hijo el Emperador, y dos antes de la muerte del cronista-, por eso Oviedo se refiere a ella como su señora. 
cauallero prudente [una palabra ilegible] su ofiçio ese día, y es mucho de doler quando la muerte saltea tales varones. Su linaje jllustre no es menester que me le digays, pues que lo dexistes en la batalla primera, en el diálogo 12, quinquagena 1 , donde se tractó del Duque su padre, e asimismo se dixeron sus armas. Pero estó maraujllado de vna cosa que he oydo deste cauallero, y es que sin tener rrenta hazía plato ordinario a los galanes e caualleros mançebos cortesanos que querían yr a comer con él. E si ello fue asy, vos lo sabrés e me direys de qué se sustentaua tanta e tan ordinaria costa como para esse plato conuenía.

ALCAIDE Dixeron la verdad. E demás de no aver Don Manrrique eredado, su padre el Duque no le ayudaua, pero el Rrey e la Rreyna Cathólicos le querían bien, e la Rreyna le ayudaua de manera que se suplía todo. E en fin, Don Manrrique gastaua en eso como lo pudiera hazer si touiera doblada la rrenta quel Duque, su padre. Finalmente, él fue tal varón que su memoria no se puede oluidar, si los historiales de su tiempo y de nuestra nasçión no perdieran sus memoriales y la rretitud de sus plumas. Porque en los años postreros de la guerra de los moros del rreyno de Granada, que se acabó el año ante [sic] que Don Manrrique muriese, se señaló muy bien su lança, como era público en España. Y avnque estonçes yo era muchacho e paje, se me acuerda muy bien e algo dello vi e lo demás lo oy muchas vezes a caualleros.

SERENO Bien será que me digais su inuençión ${ }^{15}$, quel gran ser e valor deste señor me haze dessearla, e querría oyr su letra.

ALCAIDE Era su vestido ordinario con que [una palabra ilegible] de negro e algunas vezes de pardilla, e trahía sobrel escudo de sus armas vn yelmo baúl de torneo, con el rollo e dependençias blancas vel argénteas e de goles sanguina color e por timbre vna VID, que aqueso toma por vida, con la qual e con su ordinaria tristeza de su vestir habla su letra e dize:

\section{De mi trabajo medida justa es mi propria vida.}

Y pudo muy bien dezirlo así este cauallero, porque en la verdad, nunca le faltaron trabajos.

SERENo ¿Pues a qué propósito tanta tristeza? Que los caualleros mançebos e seruidores de damas, e tan prinçipal señor que así gastaua, conuenía que a vezes fuese rregozijado para entretener e conseruar la cauallería de los cortesanos que a él e a su casa se allegauan, e no seguir estremos ni tan continuada tristeza como dezís.

ALCAIDE Todo eso hazía Don Manrrique muy complidamente, e era tan sociable e de tan linda conuersaçión que era muy quisto e amado de quantos le tractauan. E su descontentamiento era oculto, e los más lo juzgauan a que el Duque, su padre, fue muy carnal e se desabinió con la Duquesa, su muger, no por falta della sino porque ella aborresçió tantas negoçiaçiones carnales como el Duque trahía pendientes. Y avn se dixo que por lo

15 Invención y letra eran entretenimientos cortesanos y acompañan cada uno de los diálogos de las Batallas y quinquagenas, pero no hay que ser muy lince para caer en la cuenta que ambas son siempre inventos del propio Oviedo. 
mismo castigó de tal manera a vna criada suya que la señaló bien por mala muger, e fecho aquesto no quiso nj osó atender al Duque, e fuese a vn monesterio de monjas en Toledo, donde gran tiempo biuió como vna santa, biuiendo el Duque. E la Rreyna Cathólica quísola mucho e avn era su parienta, e llamáuase Doña Guiomar de Castro. E como Don Manrrique de Lara acostó e fauoresçió a la madre, pesándole al Duque deso nj le hablaua, nj le ayudaua con vn marauedí. E desta desabenençia de sus padres se dezía que era la pena e tristeza que Don Manrrique mostraua en su vestir. Pero como los juyzios de los ombres son diferentes e a vezes equivos [sic por equívocos], así diuersamente se juzgan e arbitran las inuençiones ajenas, qujen las determina es su proprio inuentor, ques el que mejor se entiende. Sus armas son las que aquí veys patentes, e tanbién la vistes e oystes discantar en el fin del diálogo del Duque, su padre. Passemos adelante, pues tractamos en desdichados fines e muertes de caualleros que conosçimos. $\mathrm{E}$ a vos toca que començeis el diálogo siguiente.

Juan Bautista de Avalle-Arge University of California at Santa Barbara 